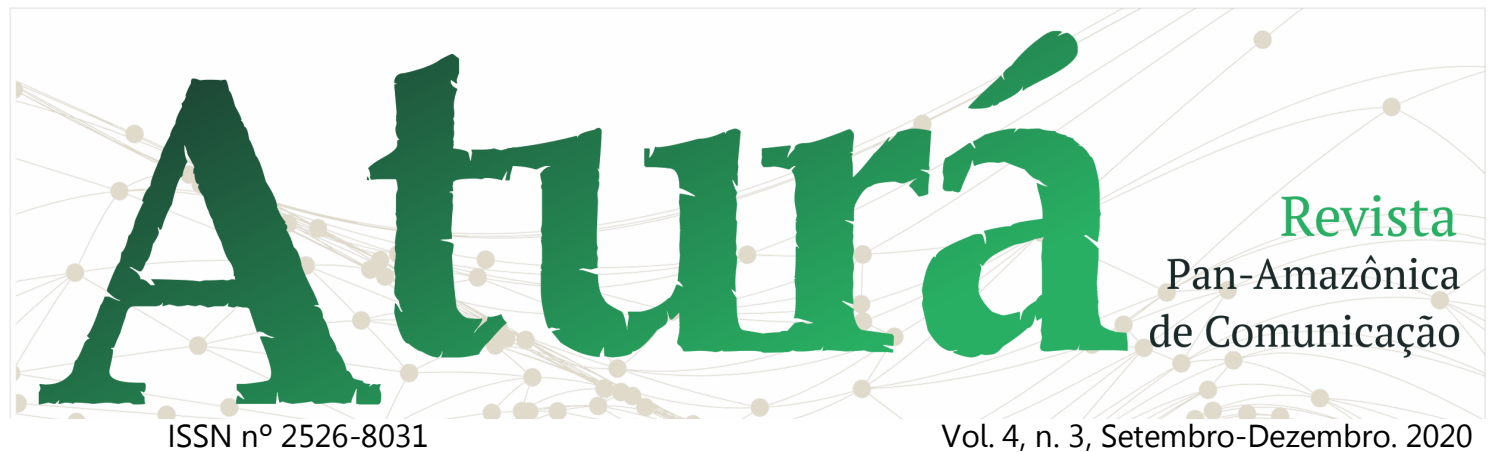

Vol. 4, n. 3, Setembro-Dezembro. 2020

\title{
MIDIATIZAÇÃO: AÇÃO OU EFEITO DE MIDIATIZAR
}

\section{Mediatization: action or effect of mediatizing}

Mediatización: acción o efecto de mediatizar

\section{Angelina de Mendonça Melo ${ }^{1}$}

\section{RESUMO}

Por meio da introdução teórica sobre o tema, percebe-se que o ato ou efeito de midiatizar, encontra-se na contextualização da cultura pós-moderna, de lógicas e operações de natureza midiática e que se inscrevem na vida da sociedade, permeando e constituindo suas formas de organização e funcionamento, definindo condições de acesso e consumo por parte dos indivíduos, sendo a partir deste consumo, os variados segmentos para determinados públicos. Com tantas especificações sobre mídia, estudar esse fenômeno é algo atraente e desafiador, pois envolve toda uma sistemática de ideias, ainda em processo de desenvolvimento infinito, já bem conceituada, por autores que abordam e abordaram o tema no decorrer de décadas por todo o mundo, alguns deles trazidos aqui neste artigo. Portanto, os estudos sobre a Midiatização é importante, por despertar aguçados sentimentos de descobertas e por sua tamanha utilidade social e pública na contemporaneidade, também pelo poder de persuasão, por intermédio da força discursiva e pela capacidade de construir variados entendimentos sobre a realidade no cotidiano.

PALAVRAS-CHAVE: Mídia; midiatização, etimologia; cotidiano; demarcação de terras; terras indígenas.

\footnotetext{
ABSTRACT

${ }^{1}$ Mestranda em Comunicação pelo Programa de Pós-Graduação em Comunicação da Universidade Federal de Roraima (PPGCOM/UFRR); Possui Graduação em Comunicação Social: Habilitação em Jornalismo pela Universidade Maurício de Nassau, Campus João Pessoa (2014.2); Especialista em Assessoria Eleitoral e Marketing Político, 300 horas pela Universidade Maurício de Nassau (2019.2); Especialista em Comunicação e Marketing Digital, pela Universidade Estratego (2021.1); Tem experiência na área de Comunicação, com ênfase em Telejornalismo, Assessoria de Comunicação e Assessoria de Imprensa; Atualmente é Mestranda Bolsista da Capes; e-mail: angelinamendonca.jornalismo@gmail.com.
} 


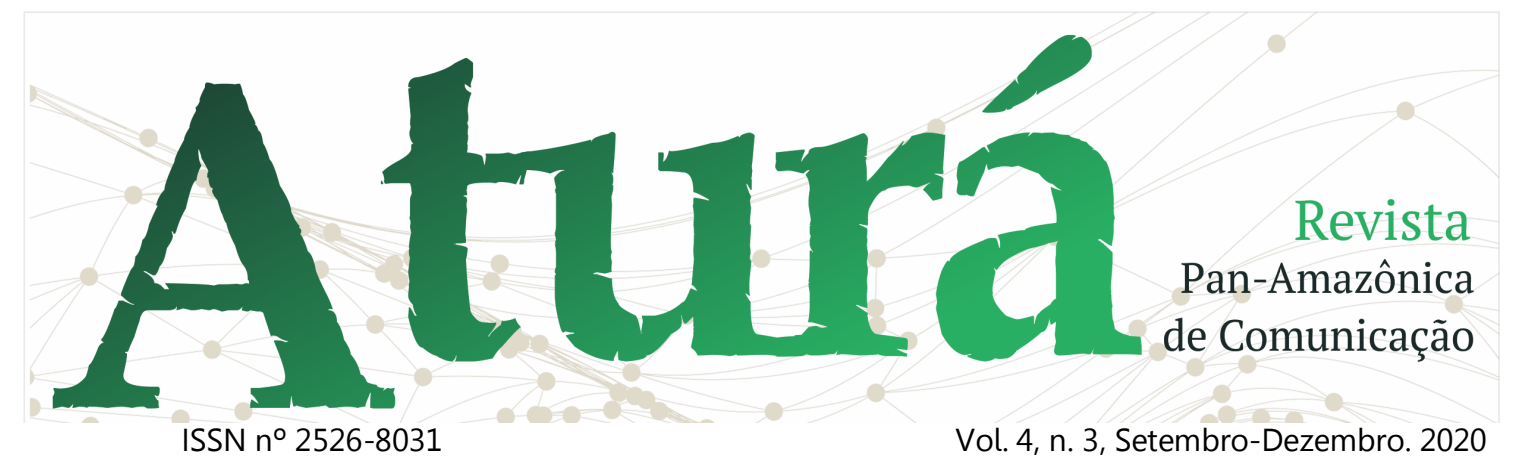

Through the theoretical introduction on the subject, it is clear that the act or effect of mediatizing is in the context of postmodern culture, of logics and operations of a media nature and that are inscribed in the life of society, permeating and constituting its forms of organization and functioning, defining conditions of access and consumption by individuals, and from this consumption, the various segments for certain audiences. With so many specifications about media, studying this phenomenon is something attractive and challenging, as it involves a whole system of ideas, still in the process of infinite development, already well-regarded, by authors who have approached and addressed the topic over the course of decades all over the world., some of them brought here in this article. Therefore, studies on Mediatization are important, for arousing keen feelings of discoveries and for its great social and public utility in contemporaneity, also for the power of persuasion, through the discursive force and the ability to build varied understandings about the reality in everyday life.

KEYWORDS: Media; mediatization, etymology; daily; landdemarcation; indigenouslands.

\section{RESUMEN}

A través de la introducción teórica sobre el tema, se desprende que el acto o efecto de mediatizar es en el contexto de la cultura posmoderna, de lógicas y operaciones de carácter mediático y que se inscriben en la vida de la sociedad, permeando y constituyendo sus formas de organización y funcionamiento, definiendo las condiciones de acceso y consumo de los individuos $y$, a partir de este consumo, los distintos segmentos para determinados públicos. Con tantas especificaciones sobre los medios, estudiar este fenómeno es algo atractivo y desafiante, ya que involucra todo un sistema de ideas, aún en proceso de desarrollo infinito, ya bien considerado, por autores que han abordado y abordado el tema a lo largo del curso. de décadas en todo el mundo., algunos de ellos traídos aquí en este artículo. Por tanto, los estudios sobre Mediatización son importantes, por suscitar agudos sentimientos de descubrimiento y por su gran utilidad social y pública en la contemporaneidad, también por el poder de persuasión, a través de la fuerza discursiva y la capacidad de construir entendimientos variados sobre la realidad en la vida cotidiana.

PALABRAS CLAVE: Medios de comunicación; mediatización, etimología; diario; demarcación de tierras; tierras indígenas. 


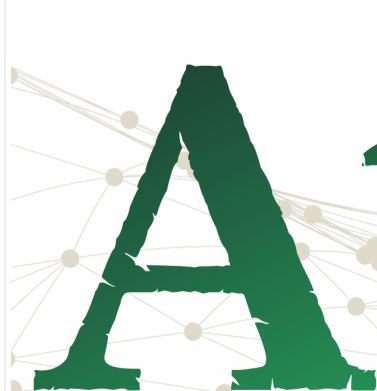

ISSN n 2526-8031

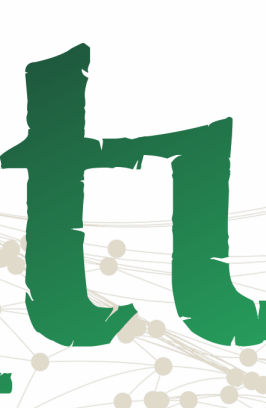

(t)

(1)

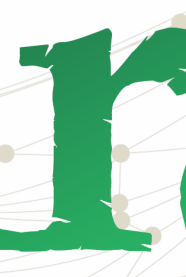

irá

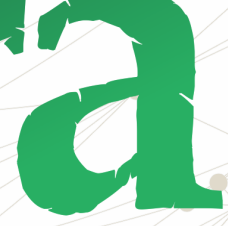

Vol. 4, n. 3, Setembro-Dezembro. 2020

\section{Introdução}

A partir da etimologia da palavra Midiatização, definimos seu conceito como a divulgação ou propagação de alguma coisa através da mídia, dos meios de comunicação, sendo o ato de tornar público por meio da mídia. Forma também aceita: Mediatização. Em seu significado mais amplo, Midiatização refere-se à etimologia Midiatizar + Ação.

Portanto, a Mídia consiste em um conjunto dos diversos meios de comunicação, com a finalidade de transmitir informações e conteúdos variados. O universo midiático abrange uma série de diferentes plataformas que agem como meios para disseminarem as informações, a exemplo, dos jornais, as revistas, a televisão, o rádio e a internet. Midiatização: ação ou efeito de midiatizar, definição do Dicionário On-line.

Este termo traz alguns conceitos de como essa ação é realizada nessas variadas mídias, também, como essa ação é introduzida no cotidiano da sociedade, ainda, como a mídia é elaborada a partir mesmo desse próprio cotidiano.
$\mathrm{Na}$ busca de aprofundamento teórico sobre o tema, percebe-se que o ato ou efeito de midiatizar, entende-se por fazer parte da existência de uma cultura pós-moderna, de lógicas e operações de natureza midiática e que se inscrevem na vida da sociedade, permeando e constituindo suas formas de organização e funcionamento, definindo condições de acesso e consumo por parte dos indivíduos. Sendo a partir deste consumo, os variados segmentos para determinados públicos.

O artigo de Sanchotene (2009), $A$ midiatização como processo de reconhecimento, legitimidade e prática social, traz uma breve introdução, acerca da Sociedade dos Meios à Sociedade Midiatizada.

Ambas evocam ambientes distintos e, consequentemente, ditam condições e parâmetros para a inserção e o funcionamento das mídias. De modo sucinto, na primeira, apesar de destaca-se a centralidade das mídias, dispositivos que estavam a serviço de determinadas funções as quais somente poderiam ser por eles realizadas em função das competências da sua própria natureza e das suas potencialidades enunciativas. Nesse caso, reconhecidos por sua função de auxiliaridade, cabendo-lhes, além de funções clássicas, conforme as prescrições de fundo funcionalista, o seu trabalho de 


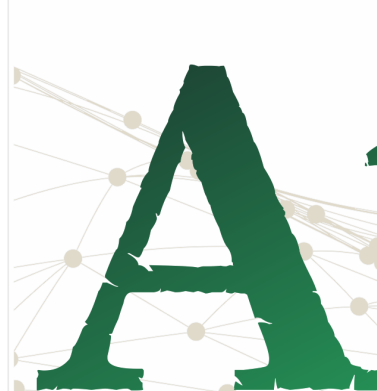

ISSN n² 2526-8031

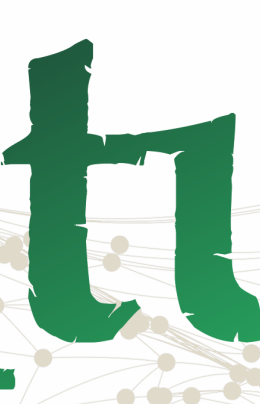

tura

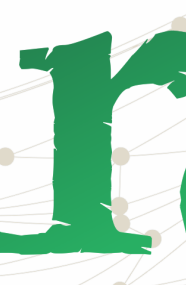

irá

Vol. 4, n. 3, Setembro-Dezembro. 2020

tematização pública (RODRIGUES, 1999 apud SANCHOTENE 2009, p. 01).

O autor Sanchotene (2009) conceitua a transformação da "sociedade dos meios" na "sociedade midiatizada" "como uma consequência da interrupção do "contato direto" entre os indivíduos pela presença das mídias."

Sanchotene (2009) acrescenta também, que a presença dos meios não é intensificada apenas no âmbito do seu próprio terreno, mas também "pelo processo de seu deslocamento e de sua expansão para outros campos. Suas operações são apropriadas como condições de produção para o funcionamento discursivo e simbólico de diferentes práticas sociais."

Sanchotene (2009) traz ainda, que os meios "já não podem ser mais entendidos como transportadores de sentidos, nem como espaços de interação entre produtores e receptores, mas como marca, modelo, racionalidade produtora e organizadora de sentido.

Portanto entende-se a midiatização, como um conceito de múltiplas vozes e com ela, numerosas versões de um único universo e falar do termo (midiatização) é um campo vasto de inúmeras possibilidades aparentes. Para contextualizar esse mundo de acontecimentos, buscamos em Gomes (2016) no artigo Midiatização: um conceito, múltiplas vozes, que traz esse contexto de um ambiente novo para esse todo e complementa o tema como um conceito chave para o mundo moderno contemporâneo. Para tanto, a midiatização já se tornou um conceito chave, fundamental e essencial para a construção da história moderna contemporânea, e com isso, com o poder único que the cabe de descrever o presente, vivência dos meios, e a mudança comunicativa que está ocorrendo de forma acelerada em todo o mundo.

Desse modo, se se tornaram parte do todo, não se pode vê-los como uma esfera separada. É necessário desenvolver uma compreensão de como a crescente expansão dos meios de comunicação muda nossa construção da cultura, da sociedade e das diferentes práticas sociais. Nessa perspectiva, a midiatização é usada como um conceito para descrever o processo de expansão dos diferentes meios técnicos e considerar as inter-relações entre a mudança comunicativa dos meios e a mudança sociocultural (GOMES, 2016, p. 01). 


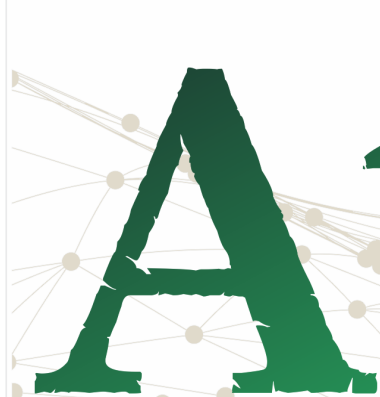

ISSN n 2526-8031

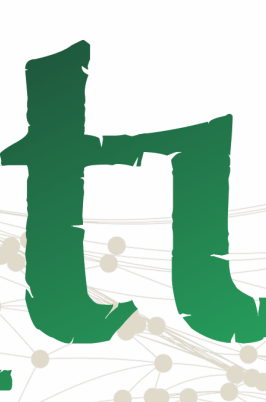

(t) 11

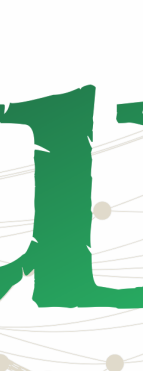

.

Vol. 4, n. 3, Setembro-Dezembro. 2020

Se referindo a um entendimento mais amplo sobre o tema, um mergulho se faz necessário ser bem mais profundo, considerando as inúmeras possibilidades em um sistema infinito. A contextualização sobre midiatização é muito ampla e não se limita há apenas um conceito claro e conciso. O autor Gomes (2016, p. 1) define bem essa imprecisão de inúmeras possibilidades, "muito embora vários pesquisadores utilizem $\mathrm{o}$ conceito de midiatização, cada um lhe dá o significado que melhor the agrada. Desse modo, o conceito de midiatização é tratado por múltiplas vozes."

Será essa diversificação um problema aparente ou uma solução ainda em construção? Para Gomes (2016, p. 2), "os estudos sobre midiatização ocuparamse com as transformações sociais e culturais nas culturas e sociedades ocidentais."

Entretanto, o processo de midiatização também se manifesta (torna-se visível) noutras partes do mundo, exibindo diferentes dinâmicas e possuindo outras consequências em diferentes contextos sociais e culturais. Será então que a midiatização constitui um processo global de mudança? Em caso afirmativo, pergunta-se onde estão localizadas as desigualdades e as dissemelhanças desse processo? Como a midiatização não se apresenta da mesma forma para todos e em todos os lugares, podem existir diferenças e semelhanças entre as culturas e nações em processo de midiatização (GOMES, 2016, p. 2).

\section{A abordagem do Pensamento Epistêmico}

Levando-se em consideração uma visão ampla que a pesquisa sobre a midiatização nos traz, surge também o questionamento sobre quando surgiu e para que surgiu a midiatização? Inquietação que foi tratada no artigo de Santos, Menezes, Fernandes e Satuf (2019), Três perspectivas sobre a midiatização $e$ suas implicações na pesquisa em Comunicação, um estudo que traz a abordagem do conceito de midiatização que tem sido empregado com frequência nas pesquisas em Comunicação para nomear fenômenos que envolvem a mídia e a sociedade, que "se trata de um conceito polissêmico e ainda em desenvolvimento. A partir de autores que assumem um claro posicionamento epistêmico." 


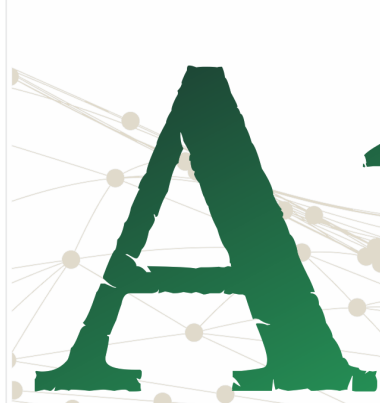

ISSN n² 2526-8031

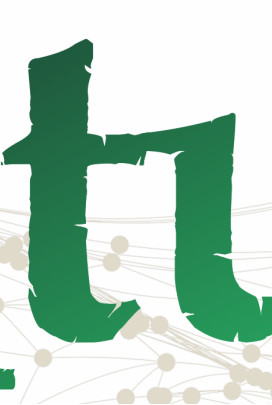

ura

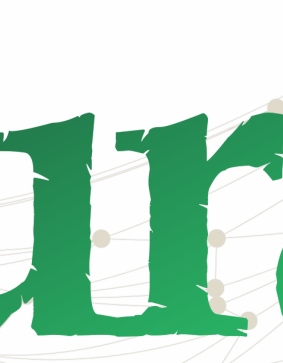

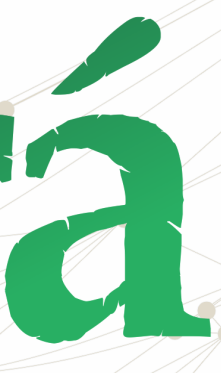

Vol. 4, n. 3, Setembro-Dezembro. 2020 de Comunicação
Pan-Amazônica
Contudo, os autores Santos, Menezes, Fernandes e Satuf (2019) afirmam que essa abordagem "semioantropológica" foi desenvolvida pelo pesquisador Eliseo Verón e que foi o argentino quem revelou essa terminologia, como sendo a fusão de várias visões semióticas e antropológicas, que estão enraizadas na tradição latinoamericana. Reforçando que outras abordagens foram fundamentadas por este pesquisador.

As outras duas abordagens estão associadas a perspectivas europeias sobre a midiatização: a abordagem "institucional", capitaneada pelo dinamarquês Stig Hjarvard; e a "socioconstrutivista", representada pelo alemão Andreas Hepp. A primeira analisa como a "lógica da mídia" atua sobre as instituições que compõem as esferas sociais (política, religião, ciência, etc.), enquanto a segunda ajusta o foco para as interações sociais propriamente ditas, ou seja, para a vinculação da mídia nas práticas comunicacionais cotidianas (SANTOS; MENEZES; FERNANDES E SATUF, 2019, p. 03).

Os autores Santos, Menezes, Fernandes e Satuf (2019, pg. 4) complementam que a perspectiva semioantropológica proposta trazida por Verón, 2011; 2014) apresenta dois eixos distintos entre si: a história do desenvolvimento midiático e a compreensão dos processos de produção de sentidos. "Trata-se, de uma visão interdisciplinar que une uma abordagem de longa duração (antropológica) e a capacidade humana de produzir e decifrar signos (semiótica)."

Para Verón (2014), midiatização é um processo muito antigo que remete à era pré-histórica do Alto Paleolítico, há cerca de 2,5 milhões de anos, quando os antepassados da espécie humana começaram a usar pedras na produção sistemática de ferramentas. Segundo o autor, uma pedra lapidada para se transformar na ponta de uma flecha, por exemplo, desencadeia um processo de produção de sentidos que indica aos membros da tribo se tratar de um instrumento de caça. Ainda que o exemplo esteja muito distante da concepção tradicional de mídia, a configuração icônica da pedra transformada em flecha atua na produção social de significados, (SANTOS; MENEZES; FERNANDES E SATUF, 2019, p. 04). 


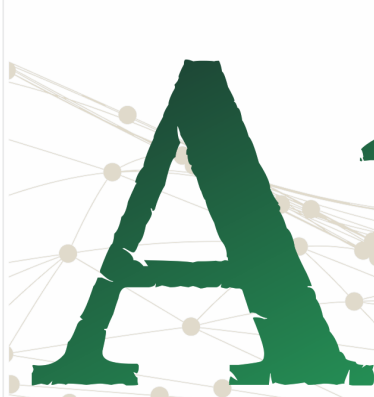

ISSN n² 2526-8031

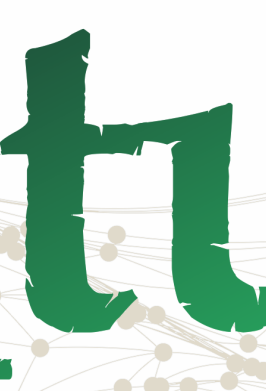

urá

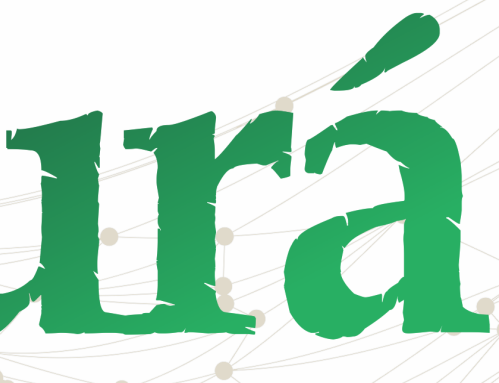

Vol. 4, n. 3, Setembro-Dezembro. 2020
O artigo Três perspectivas sobre a midiatização e suas implicações na pesquisa em Comunicação de Santos; Menezes; Fernandes e Satuf (2019), contextualiza bem o que o pesquisador Verón, trouxe de contribuição sobre midiatização para a história moderna desse conceito, ainda em construção. Essa dimensão antropológica, aborda uma perspectiva que remete a um passado distante, com dificuldades para sustentar que "a midiatização é apenas o nome para a longa sequência histórica de fenômenos midiáticos", estes que foram ao longo desses avanços tecnológicos sendo institucionalizados, em sociedades humanas com suas múltiplas consequências.

Dentre os fenômenos midiáticos mais relevantes para a compreensão histórica da midiatização, os autores Santos; Menezes; Fernandes e Satuf (2019), destacam "a ascensão da escrita, o surgimento do livro e dos jornais, o desenvolvimento de dispositivos técnicos de reprodução de som e imagem e a recente emergência da internet".
Amparada em formações humanas em contextos históricos, característica científica da antropologia, a perspectiva semioantropológica aponta uma nítida redução do tempo histórico entre $\mathrm{O}$ aparecimento de um dispositivo midiático e outro, sobretudo nos últimos séculos, quando houve uma aceleração tecnológica sem precedentes que encurtou o hiato temporal de milhares de anos (entre o surgimento da escrita e dos jornais, por exemplo) para umas poucas décadas (entre a invenção da TV e da internet).

Por sua vez, a dimensão semiótica indica a necessidade de se observar a produção e circulação de sentidos por meio de artefatos técnicos: A capacidade semiótica de nossa espécie que se expressa na produção do que chamarei de fenômenos midiáticos, consistindo a exteriorização dos processos mentais na forma de dispositivos materiais. Fenômenos midiáticos são, de fato, uma característica universal de todas as sociedades humanas", (VERÓN, 2014, p. 14, destaque no original, apud SANTOS; 


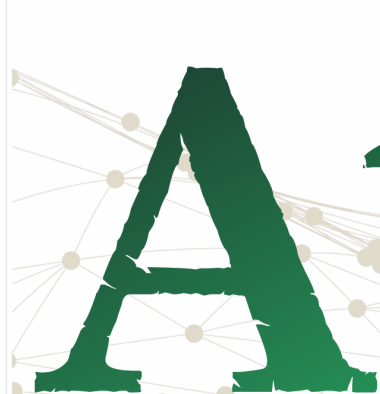

ISSN n² 2526-8031

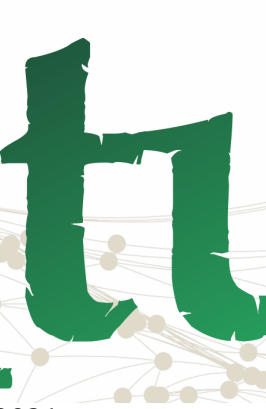

tura

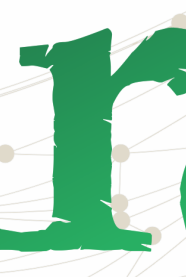

irá

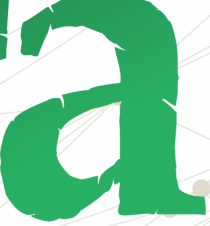

Vol. 4, n. 3, Setembro-Dezembro. 2020
Pan-Amazônica de Comunicação
MENEZES; FERNANDES E SATUF, 2019, p. $5)$.

Questionamento apaziguado em relação ao surgimento da midiatização, ainda que, de forma resumida, continua nossa jornada para responder para quê e por que esse fenômeno surgiu e permanece inquietante até os dias atuais? No artigo de Hjarvard (2012) Midiatização: teorizando a mídia como agente de mudança social e cultural, coloca a midiatização como um processo de dupla face, que transformou a mídia em uma instituição semi-independente na sociedade e tantas s outras instituições público-privadas que precisam se adaptar.

Conforme Hjarvard (2012, p. 1), "ao mesmo tempo, a mídia se integrou às rotinas de outras instituições, como política, família, trabalho e religião, já que um número cada vez maior das atividades destes domínios institucionais é realizado através tanto dos meios de comunicação interativos quanto dos meios de comunicação de massa."

Considerando esse panorama científico, de forma geral, o autor Hjarvard
(2012, p. 1) afirma também que a midiatização implica em "uma virtualização da interação social e, observando as affordances institucionais, tecnológicas e estéticas de diferentes meios de comunicação", talvez se possa entender como a mídia molda os novos padrões de interação. Assim:

A midiatização surgiu como um novo quadro teórico para reconsiderar questões antigas, embora fundamentais, sobre o papel e a influência da mídia na cultura e na sociedade. Em particular, o conceito de midiatização revelou-se produtivo para a compreensão de como a mídia se difunde para; se confunde com; e, influencia outros campos ou instituições sociais, tais como a política (Strömbäck, 2008) e a religião (Hjarvard, 2011). Este artigo apresenta os elementos centrais da teoria da midiatização e tem como ponto de partida uma questão clássica da sociologia da mídia, a saber, a saber, como a mídia interage com a cultura e a sociedade de maneira ampla. As respostas para esta questão, contudo, devem ser buscadas em uma nova condição social que vamos rotular de midiatização da cultura e da sociedade, (HJARVARD, 2012, p. 02).

Tradicionalmente, conforme Hjarvard (2012, pg. 5) "a mídia tem sido considerada como algo separado da cultura e da sociedade; consequentemente, os pesquisadores tendem a se concentrar no efeito que 


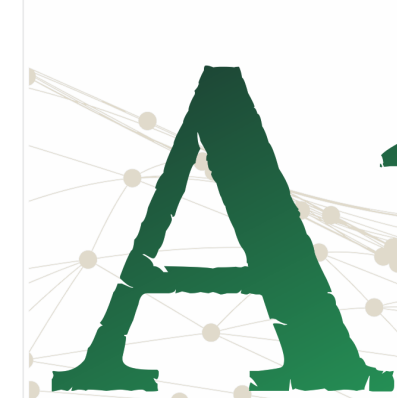

ISSN n² 2526-8031

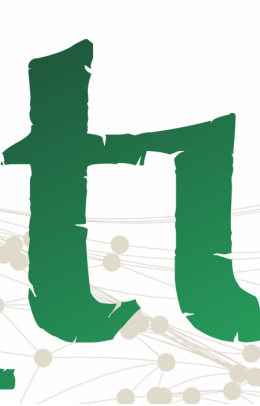

tura

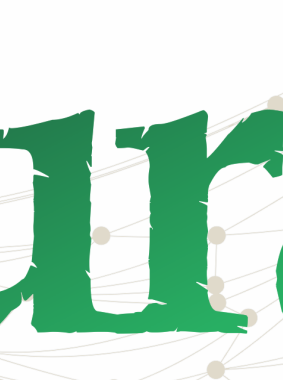

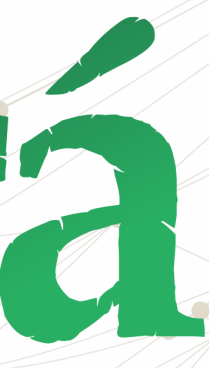

Vol. 4, n. 3, Setembro-Dezembro. 2020

Pan-Amazônica de Comunicação certas mensagens mediadas têm sobre indivíduos e instituições". A exemplo da influência que as campanhas midiáticas políticas têm sobre as pessoas, bem como, os vários anúncios publicitários divulgados na grande massa, que podem contribuir para a decisão de poder de compra desses consumidores, afetando no final da história na atenção desse mesmo grupo para assuntos mais importantes dentro da sociedade.

Hjarvard (2012, pg. 2), traz também o modo de como a sociedade reage a esse fenômeno e as suas modificações a longo prazo, "a sociedade contemporânea está permeada pela mídia de tal maneira que ela não pode mais ser considerada como algo separado das instituições culturais e sociais".

Nestas circunstâncias, nossa tarefa, é tentar entender as maneiras pelas quais as instituições sociais e os processos culturais mudaram de caráter, função e estrutura em resposta à onipresença da mídia. Esse entendimento alterado da importância da mídia não significa que questões tradicionais em relação a aspectos como os efeitos das mensagens mediadas sobre a opinião pública ou os fins para os quais as pessoas utilizam os meios de comunicação já não sejam relevantes. Mas significa, sim, que uma compreensão da importância da mídia na cultura e na sociedade modernas não pode mais se basear em modelos que consideram esses elementos de maneira separada (HJARVARD, 2012, p. 02).

Por meio dessas perspectivas trazidas pelos autores abordados neste artigo, até aqui, se torna impossível pensar sociedade sem a mídia contemporânea, ainda que esse fenômeno não seja acessível ou não chegue ao conhecimento e acesso de toda sociedade, ainda assim, o acontecimento midiático não passa despercebido.

\section{Uma analítica da midiatização}

Segue-se então variados questionamentos a respeito da importância midiática para os dias atuais. Para contextualizar esse cenário moderno, Fausto Neto (2008) ao se referir à midiatização no artigo Fragmentos de uma 'analítica' da midiatização, traz uma reflexão a respeito deste conceito, tomando como referência a evolução da sociedade dos meios para a sociedade midiatizada.

Para tanto, Fausto Neto (2008) tece inúmeras elaborações sobre este fenômeno, ao descrever sobre a sua organização e funcionamento. Além de 


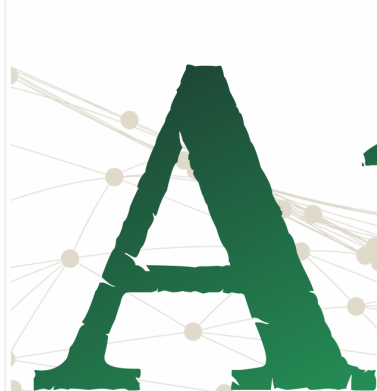

ISSN n² 2526-8031
Revista

Pan-Amazônica

de Comunicação

Vol. 4, n. 3, Setembro-Dezembro. 2020

vincular a emergência das novas estratégias interpretativas sobre a autonomia do campo que as mídias impõem.

Propondo a compreensão dessas (estratégias interpretativas), enquanto conceito associado às práticas que se estruturam e desenvolvem a partir de operações de sentido desta cultura midiática, intensas são as reflexões trazidas por Fausto Neto (2008), em seus escritos sobre o tema.

Nessa perspectiva, Fausto Neto (2008, p. 3) traz as elaborações de GIDDENS, Rodrigues e Barbero, "sobre a ação das mídias estão situadas numa processualidade em que se problematiza a existência desta modalidade de comunicação, distinta de construções nitidamente funcionais." Tal problematização mobiliza, portanto, "modelos teóricos e analíticos que vêm fornecer novos quadros explicativos sobre a sociedade e, de modo particular, o status das práticas midiáticas junto aos processos de organização e de estruturação de dinâmicas sócio simbólicas." Entretanto, ainda não está definido o que seria de fato ou viria a ser a midiatização. Nesta analítica, vários são os exemplos.

Chamam atenção para uma certa centralidade das mídias, mas enquanto um "lugar mediador" na medida em que estas se colocam como um ponto de articulação entre partes da sociedade, dependendo num grau maior ou menor, de outras dinâmicas de campos e de suas práticas sociais. Historicamente, entende-se que tal dinâmica concederia à existência dos meios uma espécie de "ação representacional". Circunstância em que co-dividiriam, com práticas de outros campos sociais, a tarefa de produção de inteligibilidades. Neste contexto de processualidades, as reflexões de Matta (1999) já esboçam a visualização dos horizontes emergentes da midiatização ao elaborar distinções entre a "cultura massiva" e a "cultura midiática", a partir da evolução dos modos de funcionamento desta segunda cultura, aponta para a existência de um "novo sujeito" (FAUSTO NETO, 2008, p. 03).

Já se referindo às tecnologias e as ações institucionais que geram novos processos de interação, segundo Fausto Neto (2008, p. 03), chama atenção para a importância dos meios e a centralidade do seu papel na análise cultural, "mas já não em seu caráter de transportadores de algum sentido (...) ou como espaços de interação entre produtores e receptores;" contudo, se faz mais evidente, "como 


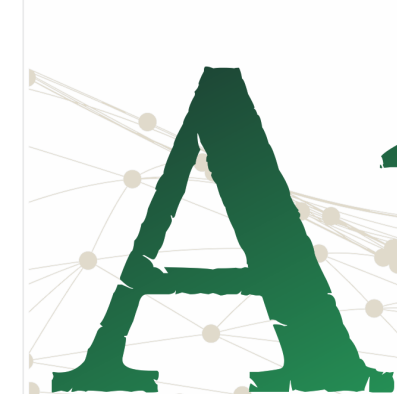

ISSN n 2526-8031
Revista

Pan-Amazônica

de Comunicação

Vol. 4, n. 3, Setembro-Dezembro. 2020

marca, modelo, matriz, racionalidade produtora e organizadora de sentido (MATTA, 1999, p. 90-91)." A partir de então, Fausto (2008) já traz alguns apontamentos do que seria de fato essa analítica.

Isto, indica pistas para a compreensão do que viria a ser a tal "analítica" da mídia, ao apontar para a conversão que sofre a tecnologia em um novo dispositivo de leitura e de organização de sentidos. Mas, a compreensão deste objeto somente se explicita, com vigor, pelos "efeitos de ruptura" entre a "visão representacional" e as hipóteses sobre a midiatização, ao atribuir-lhe um outro tipo de protagonismo atravessado por uma complexidade que não estaria situada apenas nas tecnologias, em si, mas na sua conversão na forma de meios, segundo dinâmicas de operações de sentido, no âmbito das práticas sociais (FAUSTO NETO, p. 03).

Uma palavra e um mundo de possibilidades com adaptações ao transcorrer do tempo: assim se apresenta a midiatização - atemporal, moderna, contemporânea e tão atual em suas constatações. O autor, Fausto Neto (2008), aprofunda bem esse entendimento acerca dessas inúmeras possibilidades ainda não tão bem definidas assim, pois se trata de um fenômeno ainda em evolução, reforço dizer, pois sim, se trata de algo inédito. É como se sociedade e mídia fossem uma coisa só, ou que uma não vivesse sem a outra, a história de ambas se confunde e quanto mais se busca conceituar, mas se depara com fatos novos, tão únicos, tão universais.

Fausto Neto (2008, p. 05) faz também, uma abordagem sobre "a ênfase das operações de sentido da midiatização sobre a organização social e a expansão da autonomia do campo das mídias, esta que estaria relacionada aos fatores históricos", em especial os que geram 0 funcionamento da cultura na sociedade contemporânea. E que, mesmo diante desses avanços da mídia dentro da sociedade, existe também, a "crise dos grandes relatos produz uma outra que é a inexistência de legitimidade de um discurso que pudesse sozinho articular fundamentos que viessem a ser aceitos pelos campos sociais".

Tal fato instaura novos regimes de discursividades, cuja dinâmica é caracterizada por uma equivalência geral de todos os discursos e uma certa autonomia dos seus jogos; cada um com suas regras específicas, constituindo um tipo de universo relativamente fechado (VERÓN, 1997), fazendo aparecer uma realidade destituída de pólos e de discursos centrais. Este contexto parece 


\section{A \\ ISSN n² 2526-8031 \\ Vol. 4, n. 3, Setembro-Dezembro. 2020}

preceder o que viria a ser a emergência das práticas midiáticas como um lugar autônomo que viria a se colocar como um dispositivo organizador das interações dos campos, a partir de suas competências (as mídias como lugar mediador de outros discursos). $E$ também, a própria midiatização, cuja dinâmica trataria de se impor como uma nova organização sócio-simbólica, espécie de nova dinâmica em cujas lógicas e fundamentos se estruturariam a centralidade da emergente e complexa organização social, segundo a racionalidade de um "programa tecnodiscursivo", com as tecnologias sendo convertidas em meios, segundo lógicas diferentes de práticas sociais (FAUSTO NETO, 2008, p. 05).

\section{Das Mediações e da Midiatização}

Com um olhar atualizado de um mundo ainda em constante evolução, e com o desafio de comprovar nas pesquisas o avanço da midiatização em sua constante transformação aparente, ainda a se conceituar, o autor Santi (2013), traz em seu artigo Mediação $e$ Midiatização: conexões e desconexões na análise do comunicacional, uma viagem ao universo dos "construtos teóricos das Mediações e da Midiatização", com o foco nos modelos conceituais e as suas validades para o estudo do comunicacional, além da constatação e das evidências sobre as variadas conexões desse universo.

Conforme o autor Santi (2013, pg. 12) "os problemas aí aventados são resultantes do conflito entre expectativas e observações - repousam sobre as faltas, sobre o não atendimento dos anseios patrocinados pelas armações das Mediações e da Midiatização."

E também sobre a constatação de que os resultados isolados apresentados por ambos os construtos não são suficientes à problematização integral do comunicativo. Fica claro desse modo que, neste caso, os construtos (as armações MED/MID) e seus modelos conceituais são o problema. Ambos materializam duas formas relevantes de abordagem do comunicacional e, embora apresentem afinidades teóricas, também preservam diferenças. São, portanto, essas conexões/desconexões,

afinidades/diferenças que aqui nos interessam (SANTI, 2013, p. 12).

Com as pesquisas voltadas para a análise das contribuições à problematização do comunicativo, o autor Santi (2013) aborda três eixos principais de intercorrência da midiatização: a comunicação, a cultura e a tecnologia. E, com isso, as constatações das variadas conexões acerca desses pontos.

A priori, ficam nítidas as complexidades que a mídia, por meio da 


\section{A \\ ISSN n² 2526-8031 \\ Vol. 4, n. 3, Setembro-Dezembro. 2020}

midiatização, nos apresenta. Trabalhar um tema ainda sem um conceito definido expõe quão extensos são os seus questionamentos e grandiosidade.

Constatações trazidas por Santi (2013), expõem as incertezas e as apostas nas variadas hipóteses, para definir um ambiente de contato entre as considerações originárias da mediação até a concepção do que seria a midiatização.

Complexo e atraente se torna visível o tema, com todas as suas peculiaridades. Nesse caminho, ainda segundo Santi (2013), a historicização, serviu para:

\begin{abstract}
Recuperar retrospectivamente as matrizes teórico-metodológicas que formam as Mediações e a Midiatização; serviu para emprestar estrutura aos seus construtos; para torná-los visíveis e, assim, mais sugestivos. Tal operação, embora aqui não se apresente sua completa arqueologia, permitiu observar o desenvolvimento dessas armações; ilustrar seus movimentos de formulação/ reformulação e acompanhar a sucessão gradual de suas transformações, (SANTI, 2013, p. 17).
\end{abstract}

Este procedimento (a historicização), segundo Santi (2013, pg. 17) "possibilitou desatar os construtos MED/MID de suas explicações mais tradicionais - desancorá-los - e ajudou na melhor observação dos seus conceitos e do lugar construído para eles em cada armação. Contribuiu também na caracterização da atmosfera (dos cenários) onde o pensamento acerca de tais linhas foi gestado."

Lançar mão desse recurso metodológico implicou, portanto, colocar entre parênteses as ideias que formaram a moldura ordenadora de ambas as armações e, ao mesmo tempo, escovar os conceitos manejados pelos construtos a fim de melhor revelar a sua essência envolveu a tentativa de desenterrar estes juízos dos seus enraizamentos (históricos e concretos).

Foi, a historicização que permitiu desnaturalizar as designações Mediação e Midiatização e, assim, emprestar estatuto sistểmico às suas formulações. Foi ela também (a historicização) que nos ajudou a identificar os eixos temáticos que propomos para o detalhamento das discussões. Comunicação, cultura e tecnologia passam, a partir daí, a funcionar como linhas reorganizadoras dos argumentos; como guias marcadores das conexões e desconexões, das convergências e divergências entre os construtos das Mediações e da Midiatização (SANTI, 2013, p. 13).

Durante esse percurso até aqui, vários entendimentos foram tomando forma, a epistemologia da midiatização vem ganhando força e abrindo espaço para o novo, fundamentado teoricamente, mas longe de um entendimento conclusivo. Uma verdadeira "cruzada 


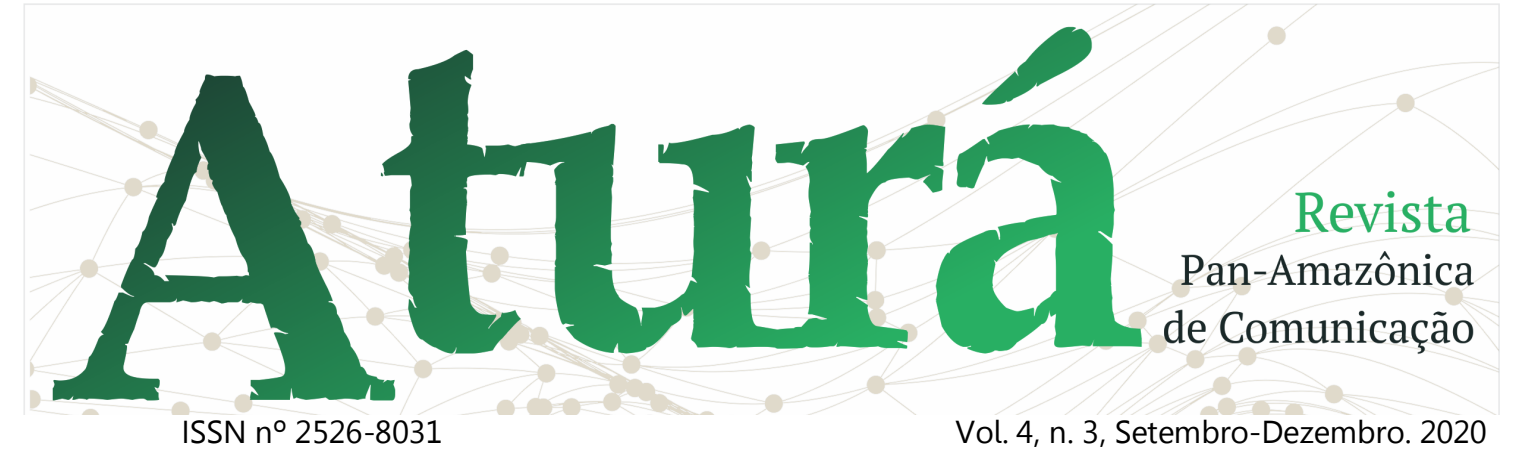

metodológica" relatada por Santi (2013, p. 18), "uma aproximação comparativa entre as armações teórico-metodológicas das Mediações e da Midiatização".

Nesta etapa trabalhamos no desenho de um paralelo teórico, no esboço de um mapa relacional entre os modelos conceituais dos construtos pareados. Aqui, depois de desfiar tais armações com a historicização, a proposta foi voltar a fiá-las - construir uma narrativa outra como forma de estabelecer um novo tecido, um novo cartograma, acerca desses construtos. Esta re-fiação é, porém, um olhar ulterior que lançamos sobre a problemática a partir do nosso ponto de vista - um ponto de vista entremeado por tais armações e pelas práticas que elas convocam/tematizam. Este fazer, em contraponto à etapa da historicização, teve caráter mais analítico e buscou, via comparação, realizar uma leitura transversal das concepções acerca das Mediações e da Midiatização. Ele implicou, portanto, reapreciar (impingir um novo apreço) os construtos manejados e reapresentar (apresentar de novo) a matriz lógica de sua construção conceitual em um novo mapa (SANTI, 2013, p. 18).

Abordar a Mediação, através das Mediatizações, demonstra o quão vasto e ilimitado é o campo da epistemologia da Midiatização contemporânea.

Mediatização inicialmente remete a várias reflexões, principalmente do que os estudiosos da modernidade contemporânea estão chamando de "mediatização". De fato, é o conceito do conceito, mais amplo e mais exigente, assim podemos dizer.

Para Moraes e Soares (2015, p. 01) no artigo $A$ era da Mediatização e suas implicações no campo da Educação, que ressalta a pesquisa em amplo crescimento, a Mediatização é "um conceito que tem sido pauta de discussões acadêmicas e que se encontra em processo de desenvolvimento." E que "novas formas de interação, novos meios e novas formas de relacionamento com os meios de comunicação, revelam os processos de transformação social e cultural, aos quais estamos vivenciando", constituindo com essa nova forma de se comunicar um esboço podemos dizer assim, de como se constituem a noção de uma nova era, a da Mediatização.

Amplo isso, não é, e retoma aqui, como se fosse novamente o início sem fim da pesquisa sobre esses fenômenos "Mediação e Midiação / Mediatização e Midiatização".

Discutir mediatização não se reduz a considerar a utilização de aparatos tecnológicos como novas possibilidades de interação. O conceito, como explica 


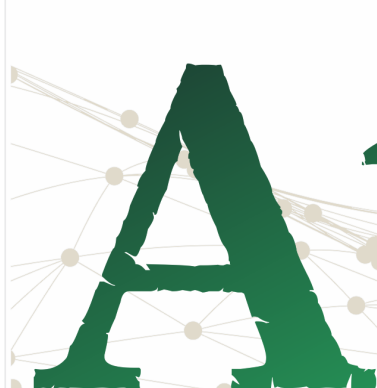

ISSN n² 2526-8031

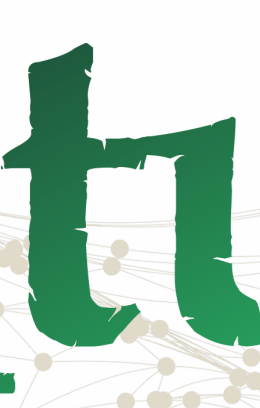

(t)

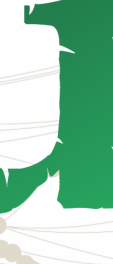

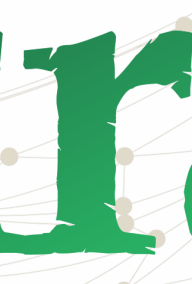

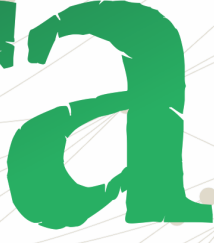

Vol. 4, n. 3, Setembro-Dezembro. 2020
Pan-Amazônica de Comunicação
Hepp (2014), abrange a "inter-relação entre as mudanças da mídia e da comunicação, e da cultura e da sociedade. Essas transformações se referem a diferentes elementos que compõem esse novo cenário em construção: as adaptações feitas pelos próprios meios que ampliaram suas formas de interação com o público, como a implantação das plataformas digitais e a utilização de aplicativos para celular; a influência sobre os temas que pautam a discussão no cotidiano; e, ainda, as novas formas virtuais que foram criadas e incorporadas no cotidiano (MORAES e SOARES, 2015 p. 01).

\section{Considerações finais}

Este artigo versou sobre um panorama universal do que seria a midiatização para os dias atuais, bem como a sua importância, e em um passeio pelo que podemos dizer mesmo que de forma bem resumida, sobre o início desse fenômeno da Midiatização e Mediatização e de como surgiu, por que e para que esse acontecimento foi batizado por fenômeno, pelos ilustres autores citados nas referências bibliográficas deste artigo.

Este artigo também apresenta os elementos centrais da teoria da midiatização e tem como ponto de partida uma questão clássica da sociologia da mídia, a saber, como a mídia interage com a cultura e a sociedade de maneira ampla. As respostas para esta questão, contudo, são buscadas em uma nova condição social que vamos rotular de midiatização da cultura e da sociedade.

Por meio dessas perspectivas, se torna impossível pensar sociedade sem a mídia contemporânea, mas que assim seja acessível, este acontecimento não passará despercebido, e pode se tornar assunto para as múltiplas mídias, com toda a sua midiatização e desenvolvimento constante.

Contudo, a própria mídia já faz parte há muito tempo do cotidiano da sociedade, com 0 seguinte questionamento, de como essa mídia é introduzida nesse meio, se a mídia modifica a sociedade, ou se a própria sociedade modifica essa mídia, sendo esse assunto para o desenvolvimento de outro artigo mais detalhado. Questionamentos sobre o tema não se limitam, pois surgem, variações sobre esse cotidiano midiático, que seria a priori, como esse cotidiano se modifica, e de que forma acontece essa modificação. 


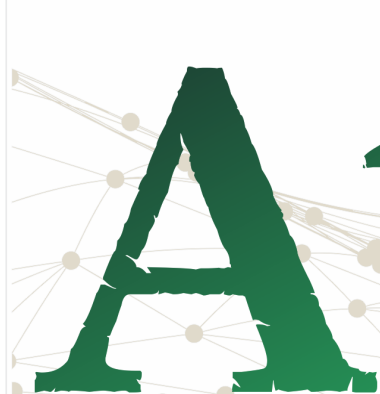

ISSN n² 2526-8031

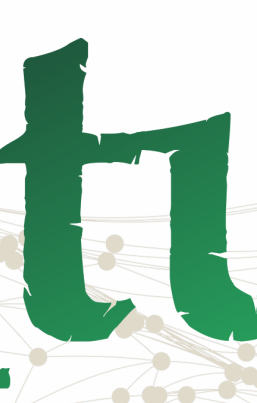

ther

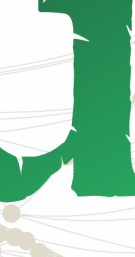

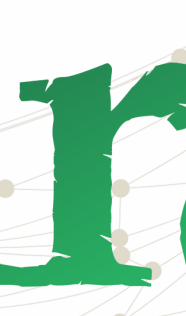

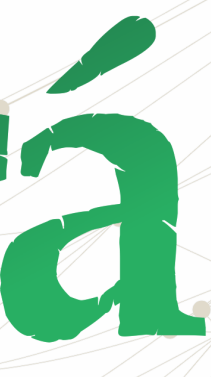

Vol. 4, n. 3, Setembro-Dezembro. 2020
Com esse breve olhar sobre Midiatização e Mediatização, já demonstra - quanto esses acontecimentos comunicacionais na contemporaneidade, são importantes e ajudam a entender os fenômenos midiáticos na sua singularidade. Contudo, aprofundar Mediatização com toda a sua epistemologia iniciada é beber da fonte instigante da sabedoria perpétua.

Podemos perceber, ainda, que se abre uma nova era na contemporaneidade, com avanços comunicacionais a todo vapor, e por isto, se faz necessário que as ciências surjam, ressurjam, e se reinventem, mais fortes e mais instigadas, assim como é sugerida a proposta deste artigo, que mesmo de forma tão simplificada e resumida, e na busca constante do entendimento desse novo reinvento da sociedade midiatizada, moderna, contemporânea, se faz necessário fundamentar incessantemente esse conceito ainda em desenvolvimento.
DICIONÁRIO, online de português https://www.dicio.com.br/midiatizacoes/, consultado em 28/09/2021.

FAUSTO NETO, Antônio. ARTIGO Fragmentos de uma «analítica» da midiatização. -Rio Grande do Sul, 2008;

GOMES, Pedro Gilberto. ARTIGO Midiatização: um conceito, múltiplas vozes; Porto Alegre, 2016;

H J A R VA R D, S t i g. ARTIGO - Midiatização: teorizando a mídia como agente de mudança social e cultural. - São Paulo, 2012;

MORAES, Elaine Cristina Gomes. A era da Mediatização e suas implicações no campo da Educação. UNESP, São Paulo, 2015;

SANCHOTENE, Carlos Renan Samuel. ARTIGO - A midiatização como processo de reconhecimento, legitimidade e prática social. - Ponta Grossa, 2009;

SANTOS, Rosa Ravena Alves; MENEZES, Aline Fiuza; FERNANDES, Bianca Sobral e Ivan SATUF. ARTIGO. Três perspectivas sobre a midiatização e suas implicações na pesquisa em Comunicação. - João Pessoa, 2019;

SANTI, Vilso Junior Chierentin. Mediação e midiatização: conexões e desconexões na análise do comunicacional / Vilso Junior Chierentin Santi. - Porto Alegre, 2013. 211 f.

\section{Referências}

